DOI: 10.2478/ausp-2019-0013

\title{
Deconstructing Language Borders through the Hybrid. A Topical Approach to Margaret Atwood's Dark Lady
}

\author{
Liana MUTHU \\ Babeş-Bolyai University (Cluj-Napoca, Romania) \\ Department of Applied Modern Languages \\ liana_muthu@yahoo.com
}

\begin{abstract}
Starting from the premise that cultures assume myriads of foreign elements, alterities, and differences, this paper analyses a phenomenon that becomes a conscious and an intentional one, namely language hybridity. Our purpose is to give thoughtful attention to certain instances of hybridity perceived at the syntactic, semantic, and lexical levels. Since language users make their choice in any situational context, we witness a great degree of linguistic blending: e.g. the borrowing of words and phrases becomes tied to new ways of making meaning. Additionally, we face a dynamic increase of mixed language registers, styles, and voices that form a complex linguistic repertoire in a literary work. For exemplification, we will analyse Margaret Atwood's experimentations across genre and linguistic boundaries encountered in her short story Dark Lady, integral part of the short fiction collection Stone Mattress. Nine Wicked Tales (2014). This narrative is characterized by a mixture of heterogeneous elements: hybrid phrases created as a result of borrowing words, elevated language (sprinkled with widely known Latin sayings), and alteration of idioms by one-word substitution. Hybridity becomes a way through which Margaret Atwood deconstructs language borders. In Dark Lady, the Canadian writer shows that hybridity stimulates innovation since the individual is allowed to move freely between spaces of meaning.
\end{abstract}

Keywords: code-switching, hybrid phrases, individual's intellectual and cultural background, situational context, verbal wit

\section{Introduction}

The need to write often leads to the search of new forms of expression. Most often, existing forms are recovered, reformulated, and revalued. In any situational context, the individual makes reference to an ensemble of accumulated knowledge 
and experiences, i.e. remembrances, happenings that have emotionally influenced him/her, reflections of previous readings, general and specialized knowledge, etc.

Artistic tradition is "a constantly evolving system of conventions, allusions, cross-references and shared expectations" (Scruton 2006: 45). In a work of art, the writer may take an enunciation or a fragment of an enunciation, previously written or uttered, and he/she may insert and fructify it in the artistic creation. This mainly consists in a well-known saying or quotation taken over without being modified; or it may be modified through the substitution of one word in a way that the newly created phrase is adjusted to a specific situational context. Therefore, a work of art, as well as a high culture, "involves a repertoire, an accumulation of works of art and exemplary utterances, which create the common ground in which the new and the surprising are planted" (Scruton 2006: 45).

The writer's creation becomes the suitable place where social and cultural diversity are depicted. This fact favours the harmonious interference between different styles, voices, social and regional dialects, etc. Such diversity is noticeable in Margaret Atwood's short story Dark Lady, integral part of the volume Stone Mattress. Nine Wicked Tales, ${ }^{1}$ published in 2014. In the same year, on $18^{\text {th }}$ September, Roberta Rubenstein wrote a review for Washington Independent, where she claimed that while Atwood's stories "tend toward darker shadings of human experience, their subtexts are often playful" due to the author's verbal wit. Indeed, the Canadian writer chooses words with precision; her pithy sentences evoke strong emotions. Her characters, the twins Martin and Marjorie, known as Tin and Jorrie, have reached an old age, and now they think back to the events they witnessed in the past. Martin - who is also the narrator - is the one who reconsiders certain occurrences through the lens of the present; his comments abound in references to previous readings from classic authors.

\section{Hybridity as reflected in language vocabulary}

In its basic sense, 'hybridity' refers to mixture. First used in biology, the term aims to designate the cross-breeding of two plant species in order to create a third, "hybrid" one. Unsurprisingly, "hybridity" was borrowed in linguistics since any natural language possesses hybrid words, ${ }^{2}$ i.e. words made up of elements taken from different languages. In English, for instance, many hybrid words combine Greek and Latin elements: this is the case of metadata, where meta is

1 It's worth noticing that Margaret Atwood deliberately chose to name her selection of short fiction "tales" and not "stories" since she gave them the air of modern myths. In a review published in The Kansas City Star on 24 October 2014, Liz Cook remarked that even if the events seemed plausible they often proved to be "slightly oversized or skewed." A hybrid word is also named 'hybridism'. 
borrowed from Greek and data from Latin. Therefore, in linguistics, hybridity is understood as "a process whereby separate and disparate entities or processes generate another entity or process (the hybrid) which shares certain features with each of its sources" (Sanchez-Stockhammer 2012: 135).

Additionally, languages possess, to various degrees, hybrid constructions that involve individuals' words, sentences, styles, manners, etc. This phenomenon has appeared as a consequence of human languages continuously evolving, adjusting themselves to a new reality: they refresh their vocabulary and experience syntactic and semantic changes. Such alterations are caused by linguistic exchanges. This may occur when two communities, living side by side, interact by exchanging ideas and cultural behaviours noticeable in the multicultural communities in our new era of globalization. ${ }^{3}$ Consequently, hybridity represents the point where cultures, and implicitly languages, get in contact. This contact favours the apparition of in-between spaces propitious for the initiation of "new signs of identity, and innovative sites of collaboration, and contestation, in the act of defining the idea of society itself" (Bhabha 1994: 1-2).

For centuries, people have borrowed words from foreign languages, creating hybrid idioms. This type of blending, known as code-switching, is the result of the contact between languages and a marked feature of our society. Switching a word in communication is the beginning of borrowing; this phenomenon occurs when the new word becomes more or less integrated into another language. An individual who uses "a word from language $A$ in language $B$ is a case of switching, but when many people do, even speakers of B who don't know A are likely to pick it up" (Spolsky 2008: 49). This is the phase when we may say that the word has been borrowed.

In most situations, a word is not taken into use at random but as a necessity to express a new reality that occurred in another culture. For instance, art deco (sometimes referred to as deco) designates an architectural style that first became visible in France just before the First World War, "using simple shapes, bright colours, and modern materials such as chrome and plastic" (Crowther and Kavanagh 2000: 25). Since this architectural style was assimilated by other countries, art deco was also adopted in the languages of the countries in question to express a new cultural reality. Then, as long as items of furniture are designed in the art deco style, hybrid phrases are always created in a language, as also noticeable in Dark Lady. In one episode, Martin smiles when looking at an old photograph "which is framed in fumed oak and resides on the dining room wall above the art deco buffet" (Atwood 2014: 88; our emphasis).

Over time, borrowing words became so frequent that newly created idioms were integrated in the vocabulary. Their foreign origin is still obvious since they

3 Marwan M. Kraidy (2005: 79) notices that globalization increases cultural diversity "as a result of the creative power of the individuals". 
have not undergone changes in the graphic form and meaning. The word belle ${ }^{4}$ is another example, now being integral part of the idiom "the belle of the ball". This is related to the most attractive woman present at a social gathering. In Margaret Atwood's Dark Lady, this idiom is endowed with another signification:

Jorrie wasn't agile, as such; more like enthusiastic. She was rangy, she was coltish, she flung herself around, and her hair slipped out of restraint. But the gang thought it was neat when the two of them took the floor together, on account of their being twins, and he could make Jorrie look like a better dancer than she was: it was his calling from childhood to defend her when possible from her own impetuousness. Also, dancing with her gave him a short respite from whatever belle of the ball he was supposed to be going out with. He had his pick, he played the field. Best that way. (Atwood 2014: 80; my emphasis)

In this context, "the belle of the ball" is not related to a reigning beauty. The reference is trivialized due to the pronoun "whatever" (or "no matter what"), which shows that the narrator, Martin, did not necessarily look for an attractive or popular woman at the ball. He may have considered beautiful either Marjorie or any woman who would have danced with him.

Another foreign word incorporated in the English language vocabulary is factotum, ${ }^{5}$ related to an individual who does all kinds of duties whether he/she likes them or not. This is present in another remark assigned by Martin to his sister, Marjorie: "She had no intention of toiling away in some tedious, soul-grinding factotum job, overworked and underpaid and a prey to oafs and thugs, the way their mother had" (Atwood 2014: 98; my emphasis). The opposite meaning is inferred since a word depends on the context in which it occurs. Additionally, the adjectives "tedious" and "soul-grinding" emphasize that Marjorie avoided doing dull and tiresome jobs.

In other circumstances, the individual may find other foreign words suitable in certain syntagmatic relations. When she remembers one of her acquaintances, Marjorie says to herself: "I worked with her on the Splendida campaign" (Atwood 2014: 79; my emphasis). The protagonist chooses to use the Italian word Splendida (spelled with capital letter) and not its English correspondent, 'splendid' or 'impressive'. In this way, Marjorie wants to show that a certain past event has a special significance to her.

4 The word belle has a Latin origin, bella. Initially, it was adopted into Old French, bele. Then, the English borrowed it in the $17^{\text {th }}$ century as a synonym for "fair" or "beautiful".

5 In the 1560s, English borrowed the word factotum 'do everything' from Mediaeval Latin. It is built up of two words: fac, imperative of facere 'to do', and totum 'all'.

6 "Soul-grinding" is created through analogy with "soul-destroying", being related to an activity that is unbearably monotonous. 


\section{Stylistic hybridity}

The concept of stylistic hybridity was first analysed by Russian semiotician and cultural theorist Mikhail Bakhtin. His distinction between organic and intentional hybridity in language is related to culture as well. For Bakhtin, organic hybridity is unintentional and unconscious, and it occurs over the course of history when several languages and cultures get in contact. In contrast, intentional hybridity is found in literary works, usually in novels, being the result of artistic intention and stylistic organization. Reading an author's literary work, we witness the diminution of borders between the author's discourse and the characters' discourse. Language stratification becomes obvious, the hybrid becomes intentional, and language registers combine within a stylistic unit. The resulting hybrid is defined as "an utterance that belongs, by its grammatical (syntactic) and compositional markers, to a single speaker, but actually contains mixed within it two utterances, two speech manners, two styles, two 'languages', two semantic and axiological belief systems” (Bakhtin 1934: 304).

A word is part of the language we speak; this language reflects the way we think about the surrounding world. Once in use, a word acquires additional meanings due to the associations between sound and sense or due to its getting into contact with other words. In a literary work, a writer exploits the expressive potential of words. Through extension, utterances may generate a multitude of meanings, values, cultural codes, etc. This stylistic hybridity belongs to the dialogic nature of language, considered an environment where alien words and voices interfere harmoniously with one another.

Language, for the individual consciousness, lies on the borderline between oneself and the other. The word in language is half someone else's. It becomes "one's own” only when the speaker populates it with his own intention, his own accent, when he appropriates the word, adapting it to his own semantic and expressive intention. (Bakhtin 1934: 293)

In a larger sense, the individual's discourse is inevitably enriched with new elements. The accumulated knowledge can be revived any time. In Margaret Atwood's Dark Lady, Martin remembers some events from his childhood, spent together with his sister. At that time, they both heard and read different kinds of narratives: some of them, probably presented in mass media, were ridiculous, but others had serious topics, being related to Greek mythology. Martin values his general knowledge by asking himself questions. He lets us know that narratives are open to interpretations: 
What had they felt about all that when they were children? They can't really recall, since they've papered over the too-frequently-repeated primal scene with so many layers of hare-brained and possibly mythological narration that the original simple outlines have been obscured. (Did the dog really run outside with a large black brassiere in its mouth and bury it in the backyard? Did they even have a dog? Did Oedipus solve the riddle of the Sphinx? Did Jason make off with the Golden Fleece? It's the same sort of question.) (Atwood 2014: 91)

Three narrative threads interweave in Martin's discourse. The first one is a sequence presumably recalled from a dog TV show. The other two are about Oedipus, who solved the riddle of the Sphinx, and about Jason, who set out on a quest for the Golden Fleece. We may notice how in one discourse distinct voices came from the past, each one having its own narrative weight and its own perspective on human existence.

Martin also has an inclination for classical antiquity. He frequently tries to find associations between real life situations and quotes from works of famous authors, especially from Roman classics. In one of his thoughts, he even integrates a line from an epigram written by Marcus Valerius Martialis:" "Oh, Jorrie, he thought. You don't understand. Men like that get tired of you once they've had you. You're in for a fall. Martial, VII: It's only pleasure, it isn't love" (Atwood 2014: 101; emphasis in the original).

In other circumstances, during the talks with Marjorie, Martin remembers his readings from the books of the English essayist Walter Pater. ${ }^{8}$ These recollections occur due to the fact that Walter Pater's life was similar to that of the narrator's: he lived together with his unmarried sisters. For this reason, Martin does not quote him accidentally when he addresses Marjorie:

'You' re only as old as you feel,' she says too frequently, while trying to talk Tin into some absurdity - rumba classes, watercolour painting holidays, ruinous fads such as spinning. [...]

'Exactly,' he replies. 'I feel two thousand. I am older than the rocks among which I sit.'

'What rocks? I don't see any rocks. You're sitting on the sofa!'

7 Marcus Valerius Martialis (known as Martial in English) is considered the creator of modern epigram. Between 86 and $103 \mathrm{AD}$, he wrote twelve books of epigrams. In his short poems, he satirized life in Rome, especially its inhabitants' scandalous activities.

8 Walter Pater (1839-1894) achieved recognition as an essayist due to his Studies in the History of the Renaissance, first published in 1873. He sustained a literary movement, art for art's sake, very popular in the $19^{\text {th }}$ century. This was "associated with the aesthetic doctrine that art is selfsufficient and need serve no moral or political purpose” (Drabble and Stringer 1990: 24). 
'It’s a quotation,' he says. 'A paraphrase. Walter Pater.' (Atwood 2014: 84; my emphasis)

The Canadian writer's short story points out that stylistic hybridity consists in deliberately juxtaposing varied discourses and perspectives within the same space. This strengthens Bakhtin's idea that language is made of a plurality of voices that mutually interfere with one another. In a literary work, hybridity becomes an artistically organized system that is "prone to generate a range of polyphonic meanings [...] whose sheer multiplicity cannot be reduced to any single omniscient narrative viewpoint" (Norris 2000: 244).

Consequently, the hybrid nature of language is the result of the individual's choice: e.g. when moving freely between spaces of meaning, the individual may incorporate and fructify generally known Latin sayings, or he/she may modify the structure of an idiomatic phrase in order to contour a new reality.

\subsection{Latin sayings}

Language cannot appear outside of a particular culture, outside of the ensemble of beliefs held by a particular community. Pithy phrases may originate from these beliefs. Proverbs are not exceptions from the rule; they have roots in real life happenings, and people choose to use them either to approve or to disprove an argument. Even if some of them date back to ancient times, they are still alive. A proverb may keep its popularity even nowadays as "a homely commentary on life and as a reminder that the wisdom of our ancestors may still be useful to us today" (Simpson and Speake 1998: x). Being deeply rooted in a culture, proverbs gradually become integral parts of the universal patrimony of humanity, and they facilitate the communication of thoughts and feelings with complex meanings. Most of them have moved from their origins migrating from one language, especially Latin or Greek, to other languages thanks to the knowledge of classic authors.

The insertion of well-known Latin sayings in an oral or a written text is the individual's personal choice. Margaret Atwood's character, Martin, uses such pithy sentences when he makes personal remarks related to his past. One of his favourites is Malum quidem nullum esse sine aliquo bono. It shows that no matter how bad a situation might be, there is always some good aspect of it. This saying represents an encouragement to a person who is overcome by misfortunes and hardships. Atwood's character fructifies it in one of his comments:

For Tin, the anecdotal family humour has long ceased to be amusing. Their mother died early, and not in a good way. Not that anyone dies in a good way, Tin footnotes to himself, but there are degrees. Being hit by a truck after closing time while jaywalking blinded with mournful tears was not a good 
way. Though it was quick. And it meant that their life was free of the oafs and thugs by the time they went to university. Malum quidem nullum esse sine aliquo bono, Tin noted in the journal he was sporadically keeping then. Every cloud has a silver lining. (Atwood 2014: 91; emphasis in the original)

Malum quidem nullum esse sine aliquo bono, followed by its English correspondent "Every cloud has a silver lining", underlines the existence of hope after a sad event. Even if Martin and his sister, Marjorie, found themselves in a predicament after their mother's death, they had the power to succeed in their professional life when going to university.

Then, even in the antiquity, there were sayings that emphasized the persuasive power of money:

'Money talks,' said Jorrie, who despite her bohemian leanings wanted to have lots of it. She had no intention of toiling away in some tedious, soulgrinding factotum job, overworked and underpaid and a prey to oafs and thugs, the way their mother had. Her nascent vision involved flashy cars and vacations in the Caribbean and a closetful of figure-hugging fabrics. She hadn't articulated that vision yet, not out loud, but Tin could see it coming. 'Yes,' said Tin. 'Money does talk, but it has a limited vocabulary.' Martial could have said that. Possibly Martial did say it. He would have to check. Aureo hamo piscari. To fish with a golden hook. (Atwood 2014: 98; emphasis in the original)

Marjorie's words, 'Money talks', is an allusion to those people who have power and influence. The woman, now aged enough, always dreamt of having more options in life, of gratifying her fancies. Aureo hamo piscari, followed by its English correspondent “To fish with a golden hook", inserted in Martin's commentary, strengthens this idea.

\subsection{Rebuilding idioms through rewording}

In general, idioms rooted in a collective mentality generate new ideas. Not only do they have their semantic content amplified, but also they could be modified and adjusted to other situational contexts. Language is a vivid reality due to its continuous process of creation and recreation.

Idioms are considered semantically hybrid since they are exposed to language creativity by deviating from their form and content. In fact, creativity means productivity. Some linguistic patterns are modified having as starting point the morphology and syntax of a natural language. ${ }^{9}$ This may occur when the

9 Language does not remain fixed or immobile in certain syntactic structures. On the contrary, as 
individual ingeniously comments upon a real life situation. He/she alters an idiom in this way by substituting one word with another one. The newly-formed structure is called "palimpsest phrase" (Lungu Badea 2004: 67). The point of reference is given by the syntactic structures rooted in a given culture. This is the case of the idiom "mutton dressed as lamb", which refers to an older woman who wears clothes that would be more suitable to a younger one. In Dark Lady, Margaret Atwood modifies the idiom:

Gone are the days when Jorrie - once known for her sultry gypsy image and her vivid African prints and her clanky ethnic jewellery - could pull off any fashion whim that caught her eye. She's lost the knack, though she's kept her flamboyant habits. Mutton dressed as Spam, he's longed to say to her from time to time, though he hasn't said it. Instead, he's clamped himself together and held himself back, and said it about other women to make her laugh. (Atwood 2014: 85; emphasis in the original)

The substitution of the noun "Lamb" with "Spam" is not accidental, the latter being a neologism related to the unsolicited messages sent via the Internet. The idiom resulted, "Mutton dressed as Spam", shows that Marjorie, now reaching an old age, is no longer attractive in the clothes usually worn by a young woman. Even if she has kept her "flamboyant habits", the decorated clothing does not help her to look showy again.

\section{Concluding remarks}

Since culture covers a wide area of human life and behaviour, language is probably the most important part of it. Human beings are inclined towards interaction, cooperation, mimicry; and this fact favours changes in a natural language even through the process of adopting words and phrases from another language. Becoming part of a new vocabulary, these borrowed words and phrases meet the demand to express a new reality; moreover, they generate endless chains of meanings, i.e. they receive new orientations in varied cultural and situational contexts.

In Dark Lady, Margaret Atwood explores the expressive value of words and, at the same time, she proves that language is a hybrid system perceived at the syntactic, semantic, and lexical levels. Firstly, the Canadian writer endows

Emile Benveniste (1974: 82, vol. 2) remarked, it functions as "a vehicle that generates meaning". Even if the number of linguistic signs is limited in a natural language, they enter in numerous combinations, fact that allows us to create an unlimited number of phrases and, through extension, of complex sentences. 
well-known hybrid idioms with new meanings (e.g. "art deco buffet", "the belle of the ball"), and she creates other hybrid constructions (e.g. "Splendida campaign", "Mutton dressed as Spam"). Secondly, she revives quotations and sayings, previously written or uttered by classic authors (e.g. Malum quidem nullum esse sine aliquo bono, Aureo hamo piscari). Margaret Atwood's choice to update pithy statements strengthens Mikhail Bakhtin's idea according to which language appears to be dialogical: everything we write or say exists in response to things that have been written or said before. This is possible because language is dynamic, relational, and engaged in a process of endless (re)description of the world.

Last but not least, hybridity may serve as a stylistic means: the dynamic increase of mixed language registers, styles, and voices forms a complex linguistic repertoire in the fictional universe created by the Canadian writer. This language hybridity allows the author to move freely between spaces of meaning.

\section{References}

Atwood, Margaret. 2014. Stone Mattress. Nine Wicked Tales. London: Virago.

Bakhtin, Mikhail. 1934. Discourse in the novel. In The Dialogue Imagination. Four Essays, 259-422. Austin: University of Texas Press.

Benveniste, Emile. 1974. Problèmes de linguistique générale, tome 2 [Problems in General Linguistics, vol. 2]. Paris: Editions Gallimard.

Bhabha, Homi K. 1994. The Location of Culture. London and New York: Routledge. Kraidy, Marwan M. 2005. Hybridity, or the Cultural Logic of Globalization. Philadelphia: Temple University Press.

Lungu Badea, Georgiana. 2004. Teoria culturemelor, teoria traducerii [Theory of Culturemes, Theory of Translation]. Timişoara: Editura Universității de Vest.

Sanchez-Stockhammer, Christina. 2012. Hybridization in language. In Philipp Wolfgang Stockhammer (ed.), Conceptualizing Cultural Hybridization: A Transdisciplinary Approach, 133-157. Berlin and Heidelberg: Springer.

Scruton, Roger. 2006. Modern Culture. London and New York: Continuum.

Spolsky, Bernard. 2008. Sociolinguistics, $6^{\text {th }}$ edition. Oxford and New York: Oxford University Press.

\section{Web sources:}

Cook, Liz. Margaret Atwood's 'Stone Mattress' tales: Not quite macabre but mildly unsettling. Book review. The Kansas City Star, 24 October 2014. https://www.kansascity.com/entertainment/books/article3248505.html (Last accessed: 6 April 2019). 
Rubenstein, Roberta. Stone mattress: Nine tales. Book review. Washington Independent, 18 September 2014.

http://www.washingtonindependentreviewofbooks.com/indexphp/ bookreview/stone-mattress-nine-tales (Last accessed: 5 April 2019).

\section{Dictionaries and encyclopaedias:}

Crowther, Jonathan-Kathryn Kavanagh, eds. 2000. Oxford Guide to British and American Culture for Learners of English, $2^{\text {nd }}$ edition. Oxford and New York: Oxford University Press.

Drabble, Margaret-Jenny Stringer, eds. 1990. The Concise Oxford Companion to English Literature, $2^{\text {nd }}$ edition. Oxford and New York: Oxford University Press.

Norris, Christopher. 2000. Heteroglossia. In Michael Payne (ed.), A Dictionary of Cultural and Critical Theory, 244-245. Massachusetts: Blackwell Publishers Ltd.

Simpson, John-Speake, Jennifer, eds. 1998. The Concise Dictionary of Proverbs, $3^{\text {rd }}$ edition. Oxford and New York: Oxford University Press. 